\title{
A qualitative study of adjustment to caring for an older spouse with psychiatric illness
}

\author{
JOANNA MURRAY* and GILL LIVINGSTON $\dagger$
}

\begin{abstract}
An understanding of ways in which older carers' perceptions of their marital relationship and duty to their spouse underlie adjustment to care-giving is required for the development of acceptable and efficacious services for spouse carers. With this aim we conducted qualitative interviews with 20 spouses of older people with a mental illness identified in a representative community study. While carers acknowledged distressing changes in their spouse, a history of reciprocity and intimacy emerged, comprising positive themes and perceived continuity which favourably influenced adjustment to care-giving. Those who still experience closeness in the relationship see themselves as coping and are reluctant to accept formal help. Others describe long-term unhappiness in marriage and experience feelings of entrapment in the role of carer. They require early and comprehensive services. Hypotheses regarding these themes are proposed.
\end{abstract}

KEY WORDS-Spouse carers, mental health, marriage, reciprocity, intimacy, qualitative method.

\section{Introduction}

Previous research into psychiatric illness and its impact upon the older married couple is extensive but it fails to address adequately the question of what kinds of services would provide effective support. Older married people generally expect that if they become ill or frail, their spouse will care for them and try to avoid sending them away to be cared for elsewhere (Tower and Kasl I 996). Being cared for by one's partner sustains morale and reduces the need for admission to institutional care (Johnson I985). But while supporting a partner with physical disabilities seems to impose no particular health risk (Johnson I 985; Livingston et al. I996), spouses of older people with psychiatric

* Institute of Psychiatry, University College London Medical School.

$\uparrow$ Department of Psychiatry, University of London Medical School. 
illness experience feelings of burden and a high rate of depression (Murray i 995).

In addition to care during illness, marriage can provide the companionship and reciprocal support which help to maintain selfesteem and morale in old age (Rook I990). Although these aspects of the relationship may be disrupted by mental illness, spouses who find meaning and reward in looking after their partners are more likely to retain good mental health (Motenko I989). Spouses tend to complain less and to seek less formal help (Cantor I983; Johnson and Catalano I 983 ) in spite of experiencing more distress and social withdrawal than other caregivers (George and Gwyther ig86; Moritz et al. I989; Brodaty and Hadzi-Pavlovic r 990; Pollitt et al. I99 I). Care-giving commonly restricts social activity, which contributes to lower morale (Thompson et al. I 993). This may particularly affect older spouses who believe they have a unique responsibility for their partner's care and cannot accept even brief periods of respite. Increasing absorption into the role and loss of opportunity to socialise may lead to 'role captivity' (Aneshenel et al. I993). When compounded by loss of attachment, troublesome behaviour and excessive demands from the spouse, the breakdown of care and admission to an institution is likely (Murray i 995). Wives seem to be at particular risk of developing a sense of subjective burden and depression (Zarit and Whitlatch I992; O’Connor et al. i990; Morris et al. г99 i Collins r 992) and because care-giving may be regarded as a continuation of the traditional role of a wife, their vulnerability may go unrecognised until a crisis occurs.

Adjustment to caring for a mentally ill spouse in later life is influenced by the pre-morbid relationship. Motivations include the longstanding reciprocity of couples who have always cared for each other, a sense of duty or obligation, and the belief that no one else could provide 'tender loving care' as well. Perceiving the continuity of a 'good' relationship is associated with higher morale and a lower sense of burden (Motenko i 989; Williamson and Schulz i 993; Gladstone i995). However, rates of depression are high both among carers who report a poor premorbid relationship and among those who perceive deterioration in the marriage since the illness (Gilleard et al. I984; Morris et al. I988; Brodaty and Hadzi-Pavlovic, i 990; Ballard et al. i 995).

Methods of coping are also implicated in successful adaptation to care-giving (Williamson and Schulz i993). Various strategies may help: for instance, acceptance may be the most effective way of coping with an irremediable decline in one's partner's health. If, on the other hand, the carer's loss of personal freedom is the major stressor, accepting respite is likely to be more beneficial. Although there are examples of successful intervention programmes (Brodaty and Peters 
I99 I ; Mittelman et al. I 993), our limited understanding of adaptation to caring for a spouse in later life probably contributes to the failure of many intervention studies to promote the well-being of older carers (Zarit and Teri i 99 I ; Knight et al. I 993). Strategies which are helpful to some carers may be experienced as critical, undermining or intrusive by others.

In order to develop hypotheses on adaptation to caring for a partner in later life and thus inform more appropriate intervention strategies, we carried out a qualitative study among respondents identified in the Islington mental health survey (Livingston et al. I996).

\section{Method}

A representative community sample of 700 subjects aged 65 or over and any co-resident adults were interviewed at their homes in inner city London, using standardised psychiatric questionnaires (for details see Livingston et al. i 996). For the qualitative study, we identified couples from among the 307 currently married individuals, in which at least one partner had a psychiatric illness. After ethical permission had been received, explanatory letters were sent to the general practitioners of all identified carers, seeking permission to approach the subjects. An appointment was made for interview at the couples' homes. To allow the carer freedom of disclosure, a second interviewer administered the Geriatric Mental State Schedule (GMS-A; Copeland et al. г 976, I 986) to the index spouse in a separate room.

For couples in which both partners were cases at screening, carer and index spouse were designated as follows: where both partners were depressed, the one with the higher depression score on the GMS-A was designated 'index' spouse and the other partner 'carer'. When one had screened positive for dementia and the other for depression, the former partner was defined as the index spouse.

Rapport was established during a structured interview on health, social difficulties and support (Murray et al. I 997 ) ; the interviewer then invited the carer to describe their marriage in the past and present. The interview guide, developed from the literature on late life marriage and caring, included the following topics:

Marital history: appraisal of early married life; happiest and most difficult times; reciprocity and mutual support; shared interests, leisure activities, decision making.

Current circumstances: social life and sources of pleasure; care-giving, coping and help-seeking; changes in the spouse and the relationship. 
Twenty qualitative interviews were conducted, recorded on audio tape, transcribed and subjected to content analysis.

\section{Results}

The sample

Sixteen of the 20 carers were women; the age range was 63 to 88 . According to the GMS-A, I 3 index spouses were cases of dementia, five had depression and two had generalised anxiety. Seven of the caregiving wives had diagnoses of depression according to the GMS-A or Clinical Interview Schedule (as applied to those aged under 65 years; Lewis et al. 1992); none of the four care-giving husbands met diagnostic criteria for mental illness.

This was a sample of working-class couples: all but one husband had worked in unskilled or semi-skilled manual occupations and i 8 couples lived in local authority rented flats. None had received formal education beyond the statutory school-leaving age. Five were in second marriages, of whom three had children from previous relationships; the other I 5 couples had had at least one child together. The majority of their children were living nearby or at most within one hour travelling time.

\section{Themes}

Content analysis was based on the topics in the interview guide. After considering carers' perceptions of their past and present marital relationships, four themes emerged from the interviews as being associated with adjustment to caring.

Regarding the pre-morbid relationship there was intimacy (the appraisal of the marriage as intimate or distant), and reciprocity (presence or absence of mutual support, and shared decision-making and resources). Regarding present circumstances there was continuity in the relationship (and in the carer's regard for the spouse), and ways of coping and attitudes to support.

In the following discussion of these themes, quotations from the interviews are identified by the GMS or CIS 'diagnosis' of the carer first, and by that of the spouse second.

\section{Intimacy in the pre-morbid relationship}

The majority had married young and their early married lives were characterised by wartime hardship, bringing up families on low incomes. Modest expectations of marriage underlie their appraisals: 
positive descriptions of husbands include 'hard worker' or ' good to the children'. There was a clear demarcation of roles in most marriages and few considered their relationships to have been close or confiding. Similarly little mention was made of companionship, although there were some shared interests, particularly home decorating, holidays and family outings.

He was my (first) husband's cousin. I was 44 and he was 50 . He is the sort of man that loved children and they loved him. He took on my three and we had a daughter of our own. In the early years it was hard for everybody but happy enough with the children (wife with depression; husband with dementia).

When my father took me to the church, he said to me, when Stan puts that ring on your finger you will never want for a crust of bread and I never have. My father's words was right. We have always had a happy marriage (wife, no diagnosis; husband with anxiety).

Although a minority reported hostility in the relationship, equally there were very few positive recollections of romantic love or nostalgia for the early days:

I was I 4 when I met my husband and I 7 when I got married. We had a good life. I've worked and he's worked. We never saved anything to be honest about it. We had a good life, went on trips and everything. It's been a very, very, very happy marriage. But as for 'nature' or anything like that, that's all finished with now. I could walk around naked and he wouldn't take any notice because he's not with it. Till his illness it was very good (wife, no diagnosis; husband with dementia).

Others described marriages with little companionship and affection for many years prior to their spouse's illness. They reported lack of intimacy, few shared interests and inequality of responsibilities. In addition, some criticised aspects of their partner's personality. Enduring behaviour patterns which had caused distress for many years were now exacerbated by illness.

You want the truth, don't you? It's not been happy. He left for work at six in the morning and came home at Io and at weekends we never saw him. So basically I brought up the family on my own. In those days you had no option, you made your bed and you had to lie on it (wife, no diagnosis; husband with depression).

We married when I was 47 and he was a widower of 42 with three children. It's not been at all happy. He's always had a temper ... got big ideas. I daren't look at anybody or he thought I was carrying on with them (wife with depression; husband with dementia).

It's been lonely. He's not one for going out. Work came first. He wouldn't do anything different, just go to work, come home, have his tea and that was it. He's not a man to talk about anything or show his feelings (wife with depression; husband with depression). 
We didn't really have a lot in common. Of course I didn't know that when I was young because I was very into dancing and so was he. He was a marvellous dancer. Then as the years went on I found that we really didn't have other things in common. For years now I've faced it every Saturday, he'd come in and always pass silly remarks, looking for an argument. He would go on and on until I'd say something (wife with depression; husband with dementia).

Only wives expressed the feeling of being trapped in the role of carer. They would not have chosen to spend so much time at home but felt unable to leave their husbands alone; going out together was not considered an option. Some were reluctant to invite friends and family into the home because of their spouses' unsociable behaviour. This was usually a continuation of a lifelong pattern:

We've got nothing in common. He had the idea that once the children was grown up, I'd go to the pub with him, but I wouldn't do that. If the family wasn't round I could do what I liked and if he didn't like it, it would be his hard luck! He does what he wants to do (wife, no diagnosis; husband with depression).

\section{Reciprocity in the pre-morbid relationship}

A 'good' marriage involved sharing resources, giving and receiving practical and emotional support, making a return for help given in the past. These aspects of reciprocity were mentioned often in the interviews. Past problems, illness and bereavement were recalled as times of mutual support for some couples:

There's not really been any bad patches, only when there were deaths in the family. Then we always looked after each other, comforted each other (husband, no diagnosis; wife with anxiety).

Others recalled family crises and tragedies when their partners had let them down:

When I lost my daughter (aged nine, in a road accident) I think he put his feelings over to the other daughter. He tried to give her all that he'd never given her before. He didn't give me much support. I brought the family up on my own (wife, no diagnosis; husband with depression).

With very limited incomes, most respondents believed that fairness with money was the sign of equality and trust between partners:

We have always done things together and shared everything. We've never been artful to each other. Like some men never let their wives see their wage packet. The little bit of money we have got is a share out. To me, if you're married you're not separate, you're one (wife, no diagnosis; husband with dementia). 
In contrast, secrecy about money and withholding too much of the weekly wage signified a poor marriage:

He's mean, very, very mean. I wouldn't see him want for anything. He only ever gave me thirty pounds a week and there were three children to feed (wife with depression; husband with dementia).

Discussing problems and reaching decisions together were considered important aspects of a happy marriage. Some wives had never experienced this mutuality in their marriages:

He's selfish.... 'I'm all right, get on with it yourself', that's all he cares. You couldn't make no decisions with him. Couldn't discuss anything with him. Whatever you said he'd take no notice (wife, no diagnosis; husband with dementia).

He doesn't want to know about anything, not any worry or trouble, he never did. He never wanted to make decisions. It has its good points, he didn't mind what you were doing. He wouldn't ask me what I was spending. But sometimes I think oh God! I wish I hadn't all this to be bothered about (wife with depression; husband with dementia).

\section{Continuity in the relationship}

Changes in the spouse's characteristic behaviour and mood caused distress to all respondents. Nevertheless, those who perceived continuity in the relationship despite these changes were able to tolerate the difficulties with more understanding:

He's changed a lot, a lot. But he's still a very kind man. Now and again he gets a bit whatsaname but it's his complaint, isn't it? I say to him 'Stop it!' and he's all right (wife, no diagnosis; husband with dementia).

Although there was no mention of major disruption to life plans, all carers had to take increasing responsibility for decision-making, finances and domestic tasks, in addition to providing personal care. Outings and holidays were restricted. Some accepted this as a phase of marriage in later life and continued to enjoy each other's company in spite of the limitations. Providing support was not regarded as burdensome in these circumstances. While many wives resented the changes in familiar patterns of exchange and the interference with their social lives, care-giving husbands felt able to continue with their normal activities, albeit at a reduced level. Acceptance of their partners' limitations seemed to play a part in maintaining continuity in the relationship:

We like each other's company. Always did things together. She doesn't go out now. We only watch TV and read the papers (husband, no diagnosis; wife with anxiety).

I am always buying her flowers because I have always done so. Every week 
they are there as you saw on the table. I always cheer her up with things like that or saying 'come on, let's go out.' I say to her when you feel right we will go. That helps her. She thinks she is a burden but she is not (husband, no diagnosis; wife with dementia).

Although mental illness might lead to trying behaviour, carers who accepted this as part of the illness continued to hold their partners in high regard, and to return the kindness with which they had been treated in the past:

He's a good man, never nasty. When I'm not well he makes such a fuss of me and gets very worried. He's gentle, never loses his temper. But he's got no interest and he can't do anything. He appreciates what I do for him though. He says 'you're a good wife' (wife, no diagnosis; husband with depression).

I wouldn't have nobody in to look after him. He's the main one. He has never hurt me or nothing, been a kind man. I could never hurt him, we've been together too long for that (wife, no diagnosis; husband with dementia).

\section{Coping and support}

Acceptance of the spouse's declining health may be an effective means of coping with unchangeable sources of stress. Making the best of the situation in adjusting to the role of carer seems to preserve a sense of continuity in the marital relationship.

He sits in the chair and he's fast asleep. I mean, there's no company there really. I tend to put the telly or wireless on and forget about it. I never let anything get me down. You mustn't, not with a complaint like he's got (wife, no diagnosis; husband with dementia).

Another wife, in trying to help her daughter adjust to their father's illness, shows that she has maintained her positive regard for her husband by accepting the changes in his behaviour:

My Joan worries more about her dad than what I do. I mean I'm used to seeing Stan as he is but she's not. When we went down there for Easter she was really upset. She said it's not my dad is it, he's so quiet. I said of course it's your dad. He's always been quiet, it's just he's more quiet now (wife, no diagnosis; husband with anxiety).

Coping was sometimes a matter of emotional release, of having 'a good cry' in private and feeling better for it. Venting anger and frustration was beneficial for some, although it could add to their spouse's distress:

I swear a lot, he drives me to it, but it upsets him. He can't bear it. I throw things, break plates. I broke that clock on the wall. He drives me round the bend. He called me up to him thirty-nine times the other day. I cry, sometimes I can't stop (wife, no diagnosis; husband with depression).

I lose my temper and we swear at each other. I feel I want to cry my eyes out. 
I can't talk to my friend because he won't let me go downstairs to see her. $\mathrm{He}$ says you're my wife you can't go out (wife with depression; husband with dementia).

Feelings of helplessness and depression were most pronounced in those who had not accepted the nature of their spouse's illness. Some wives resented what they saw as uncooperative behaviour and unreasonable demands. High dependency was especially difficult to tolerate in a relationship built upon the husband's traditional role as provider. Tension between one couple, for example, was constantly high, the wife frustrated by her husband's 'unwillingness' to try to stand unaided and he angry at her reluctance to accept the extent of his disabilities. The wife had enlisted a considerable amount of support from a variety of sources. This enabled her to cope with most practical tasks, though not with the emotional impact of her husband's dependency and of their disrupted retirement plans. Respite care was essential in enabling her to spend time apart from her husband.

Another wife, who recalled long-term marital conflict, had readily accepted formal help. However, she still found the burden of care too much:

A night nurse comes every night to put him to bed, but I want someone to come in the morning to wash and dress him. I like to go out and see people but he's not sociable. We used to go to the day centre but I had to sit with him all the time not talking to anyone. He should go into a home. I can't look after him, he's making me ill (wife with depression; husband with dementia).

Others guarded their independence in running the home and caring for their partners. They would not accept formal support until they were unable to manage any longer. Coping with the tasks was a source of pride:

I'm defiantly independent. I don't like other people to come and rock the boat. I don't sit still for long, I'm always up and on the go. To ask people to help would be the last straw (husband no diagnosis; wife with depression).

The following quote comes from an 89-year-old man who, each day, washes and dresses his very frail wife who is blind and unable to speak. His wife had been admitted to residential care while he himself was in hospital. Seeing her distress in unfamiliar surroundings, he had brought her home after two weeks, long before he had recovered his own mobility:

I was very active until two months ago when I broke my hip. I like to do all the shopping and cooking but with two sticks I can't do it at the moment. I hope she goes before me because no one would be able to look after her. She'd have to go into a home. It would make her depressed (husband, no diagnosis; wife with dementia). 
Most carers were reluctant to ask their children to help more, although they were assured that their family's support would be there when needed. Frequent visits and phone calls from children and grandchildren were the main source of pleasure. In many cases, sons and daughters had become the main source of emotional and practical support years before the illness had been diagnosed. There were instances of lost contact with children, but only one case where this was attributed to the illness.

His children have all got cars but they don't come and take us out. I ain't gonna eat humble pie and ask them. Nobody don't want you. I think it's because of him really (wife with depression; husband with dementia).

\section{Discussion}

In this qualitative study we explored ways in which carers' perceptions of their marriage and their duty towards their spouse, underlie adjustment to care-giving, ways of coping and distress. Marital history, shared interests, intimacy and companionship are all related to quality of marriage in later life (Rook I990). We anticipated that continuity in these factors and in carers' regard for their spouses would influence adjustment to care-giving (Motenko i 989).

The disappointing outcome of many interventions offered to this vulnerable group has been attributed to their reluctance to accept formal support (Barusch i988; Montgomery and Borgatta i989; Murray et al. I $997 a$ ). In order to devise appropriate interventions for couples, we must first understand the impact of mental illness upon the relationship, by disentangling longstanding patterns from the acute disruptions associated with the illness (Zarit and Edwards I 996). The present study has enabled us to explore this further and to develop hypotheses.

In discussing the dementia of his wife John Bayley had no doubt that their shared sense of humour was the key element in maintaining their relationship:

Mental deterioration may disturb the free-and-equal give-and-take of married intercourse. One partner may no longer be able to think or speak as he or she once did. But the tenderness of humour survives even this deadening interruption of the old relationship. Never mind about 'caring'; the main thing in a marriage of senility is to retain, from the resources of its past, enough mutual understanding to produce and prolong a togetherness of jokes (Bayley I997).

Though lacking his elegance of expression, some carers in our sample clearly shared his belief in the endurance of companionship in the face 
of severe mental illness. Those who had adjusted more positively to care-giving accepted that the changes in their partner were the result of the illness and, although this was a cause for sadness, their attachment remained strong. Our interviews suggest that those who have enjoyed reciprocity in marriage, continue to feel affection for their spouses and are more willing to cope with the demands of caring. Symptoms of depression were more common in carers motivated by a sense of duty alone. While it is axiomatic that low mood is associated with negative cognitions about the past, carers' accounts of their marital histories suggest that these thoughts were present before the onset of their spouse's illness.

Although it is an oversimplification to divide spouse carers into groups, two themes emerge as underlying adaptation, or lack of adaptation, to caregiving. First, carer mental health is maintained when there is recognition of some continuity in reciprocity and intimacy. This group may be reluctant to accept formal help, resenting the intrusion and wishing to care for their own spouse. However, deterioration in their own or their spouse's health may lead to a need for services. Our hypothesis is that at such points of crisis, this group will accept whatever help they see as being in the best interest of their spouse. In these circumstances, these carers benefit from practical help to assist them to continue caring. Secondly, those who look back on marriages that have been low in intimacy and reciprocity, derive no satisfaction from care-giving and are themselves at risk of mental illness. They attribute this to being trapped by the demands of their spouse. They require and accept formal support at an earlier stage, to encompass their need to reduce the burden of caring and also in response to their own depression.

Successful interventions with older couples depend upon identifying the long-term patterns of reciprocity and intimacy within the marriage and need to distinguish between these two groups. Access to help for the former group should be targeted by providing written information on local services (e.g. respite care) available through primary and secondary care, neighbourhood social services and non-statutory carer groups. The general practitioner has a key role in monitoring the wellbeing of both partners and responding to signs of acute distress. Carers in the second group require more intensive intervention and, in some cases, the opportunity to relinquish care-giving. Our conclusion is that services which relieve feelings of entrapment should be targeted at this group.

Further studies are required to confirm these conclusions about the relationship between aspects of marital quality, the development of 
mental illness in carers, and the acceptability and efficacy of targeting interventions in this manner.

\section{Acknowledgements}

We wish to express our gratitude to the Islington couples who welcomed us into their homes and took part in long interviews. The study was funded by a grant from the Department of Health.

\section{References}

Aneshensel, C. S., Pearlin, L. I. and Schuler, R. H. I 993. Stress, role captivity and the cessation of caregiving. Fournal of Health and Social Behaviour, 34, 54-70.

Ballard, G. G., Saad, K., Coope, B., Graham, C., Gahir, M., Wilcock, G. and Oybode, F. I995. The aetiology of depression in the carers of dementia sufferers. Fournal of Affective Disorders, 35, 59-63.

Barusch, A. S. i 988 . Problems and coping strategies of elderly spouse caregivers. The Gerontologist, 28, 677-85.

Bayley, J. i997. The Times. London, 22 April.

Brodaty, H. and Hadzi-Pavlovic, D. i 990. The psychological effects on carers of living with dementia. Australia and New Zealand Fournal of Psychiatry, 24, 35 I-6I.

Brodaty, H. and Peters, K. E. I99I. Cost effectiveness of a training program for dementia carers. International Psychogeriatrics, 3, I I-22.

Cantor, M. H. I983. Strain among caregivers: a study of experience in the United States. The Gerontologist, 23, 597-604.

Collins, C. r 992. Carers: gender and caring for dementia. In Arie, T. (ed), Recent Advances in Psychogeriatrics, 2, I 53-6 $\mathrm{I}$. Churchill-Livingstone, Edinburgh.

Copeland, J. R. M., Kelleher, M. J., Kellett, J. M., Gourlay, A. J., Gurland, B. J., Fleiss, J. L. and Sharpe, L. I976. A semi-structured clinical interview for the assessment of diagnosis and mental state in the elderly. The Geriatric Mental State Schedule: I Development and Reliability. Psychological Medicine, 6, 439-49.

Copeland, J. R. M., Dewey, M. E. and Griffiths-Jones, H. M. i986. A computerised psychiatric diagnostic system and case nomenclature for elderly subject: GMS/ AGECAT package. Psychological Medicine, r6, 89-99.

George, L. K. and Gwyther, L. P. i 986. Caregiver well-being; a multi-dimensional examination of family caregivers of demented adults. The Gerontologist, 26, 253-9.

Gilleard, C. J., Bedford, H., Gilleard, E., Gledhill, K. and Whittick, J. E. i 984. Emotional distress amongst the supporters of the elderly mentally infirm. British Fournal of Psychiatry, 145, I $72-7$.

Gladstone, J. W. I995. The marital perceptions of elderly persons living or having a spouse living in a long-term care institution in Canada. The Gerontologist, 35, 52-6o.

Johnson, C. L. I 985 . The impact of illness on late-life marriages. Fournal of Marriage and Family, I65-72.

Johnson, C. L. and Catalano, D. I983. A longitudinal study of family supports to impaired elderly. The Gerontologist, 23, 6 г 2-I8.

Knight, B. G., Lutzky, S. and Macofsky-Urban, F. I993. A meta-analytic review of interventions for caregiver distress: recommendations for future research. The Gerontologist, 33, 240-8.

Lewis, G., Pelosi, A. H., Araya, R. and Dunn, G. i 992. Measuring psychiatric disorder in the community. A standard assessment for use by lay interviewers. Psychological Medicine, 22, 465-86. 
Livingston, G., Katona, C. and Manela, M. i996. Depression and other psychiatric morbidity in carers of elderly people living at home. British Medical Fournal, 312, I $53-6$.

Mittelman, M. S., Ferris, S. H., Steinberg, M. A., Shulman, E., Mackell, J. A., Ambinder, A. and Cohen, J. r 993. An intervention that delays institutionalization of Alzheimer's Disease patients: treatments of spouse-caregivers. The Gerontologist, 33, $730-40$.

Montgomery, R. J. V. and Borgatta, E. F. I 989 . The effects of alternative support strategies on family caregiving. The Gerontologist, 29, 457-64.

Moritz, D. J., Kash, S. V. and Berkman, L. F, I989. The health impact of living with a cognitively impaired elderly spouse. Fournal of Gerontology, 44, 5 I 7-27.

Morris, R. G., Morris, L. W. and Britton, P. G. I 988. The relationship between marital intimacy, perceived strain and depression in spouse caregivers of dementia sufferers. British Fournal of Medical Psychology, 6r, 23 I-6.

Morris, R. G., Woods, R. T., Davies, K. S. and Morris, L. W. i 99 I. Gender differences in carers of dementia sufferers. British fournal of Psychiatry, $\mathbf{5}^{\mathbf{8}}$ (Suppl. го), 69-74.

Motenko, A. K. I989. The frustrations, gratifications and well-being of dementia caregivers. The Gerontologist, 29, I66-72.

Murray, J. I 995. Social support and coping styles. In Murray, J., Prevention of Anxiety and Depression in Vulnerable Groups. Gaskell, London, 50-2.

Murray, J., Manela, M., Shuttleworth, A. and Livingston, G. I $997 a$. An intervention study with husband and wife carers of older people with a psychiatric illness. Fournal of Affective Disorders, 46, 279-84.

Murray, J., Manela, M., Shuttleworth, A. and Livingston, G. I997b. Caring for an older spouse with a psychiatric illness. Aging and Mental Health, I, 256-6o.

O’Connor, D. W., Pollitt, P. A., Brook, C. P. B. and Reiss, B. B. I990. Problems reported by relatives in a community study of dementia. British Fournal of Psychiatry, I56, 835-4I.

Pollitt, P. A., Anderson, I. and O'Connor, D. W. i99 I. For better or for worse. The experience of caring for an elderly dementing spouse. Ageing and Society, I I, 443-89.

Rook, K. S. i 990. Social relationships as a source of companionship: implications for older adults' psychological well-being. In Sarason B. R., Sarason, I. G. and Pierce, G. R. (eds), Social Support: an Interactional View. New York: John Wiley, 2 I 9-50.

Thompson, E. H., Futterman, A. M., Gallagher-Thompson, D., Rose, J. M. and Lovett, S. B. I 993. Social support and caregiving burden in family caregivers of frail elders. Fournal of Gerontology, 48, s245-s54.

Tower, R. B. and Kasl, S. V. i 996 . Gender, marital closeness and depressive symptoms in elderly couples. Fournal of Gerontology, $\mathbf{5}_{\mathbf{I}} \mathbf{B}$, I I $5^{-29}$.

Williamson, G. M. and Schulz, R. I993. Coping with specific stressors in Alzheimer's disease. The Gerontologist, 33, 747-55.

Zarit, S. H. and Teri, L. I 99 I. Interventions and services for family caregivers. Annual Review of Gerontology and Geriatrics, I I, 287-3 10.

Zarit, S. H. and Whitlatch, C.J. I992. Institutional placement: phases of the transition. The Gerontologist, 32, 665-72.

Zarit, S. H. and Edwards, A. B. I996. Family caregiving: research and clinical intervention. In Woods, R. T. (ed), Handbook of the Clinical Psychology of Ageing. John Wiley, Chichester, 333-68.

Address for correspondence:

Accepted 4 February $199^{\circ}$

Joanna Murray, Section of Epidemiology and General Practice, Institute of Psychiatry, De Crespigny Park, London $\mathrm{SE}_{5} 8 \mathrm{AF}$ 